\section{Lexicografia pedagógica $e$ multimodalidade: análise de verbetes ilustrados de um dicionário infantil da língua portuguesa}

Pedagogical lexicography and multimodality: a children's dictionary illustrated entries analysis

Aryanne Christine Oliveira MOREIRA (UECE) aryanne.moreira@aluno.uece.br Raoni Reinaldo CORIOLANO (UECE) raoni.coriolano@aluno.uece.br

Recebido em: 30 de set. de 2020. Aceito em: 14 de out. de 2020 .
MOREIRA, Aryanne Christine Oliveira; CORIOLANO, Raoni Reinaldo. Lexicografia pedagógica e multimodalidade: análise de verbetes ilustrados de um dicionário infantil da língua portuguesa. Entrepalavras, Fortaleza, v. 11, n. esp., p. 261-278, ago. 2021. DOI: 10.22168/2237-6321$10 e s p 2121$.

Resumo: Sob a perspectiva da Lexicografia Pedagógica (WELKER, 2008; PONTES, 2009; DURAN, 2008), os dicionários devem ser produzidos conforme as necessidades de aprendizagem do público para o qual se destinam. Além disso, tendo em mente as ideias da Multimodalidade (KRESS, 2015; JEWITT, 2014), compreendemos que vários modos semióticos podem se organizar entre si para compor uma unidade maior de significado, assim, observamos serem os verbetes ilustrados de dicionários infantis possíveis exemplos de tais unidades maiores. O presente estudo objetiva analisar verbetes ilustrados, com base nas metafunções da Gramática do Design Visual (KRESS; VAN LEEUWEN, 2006). Para tanto, selecionamos como objeto de estudo a obra Aurelinho: Dicionário Infantil Ilustrado da Língua Portuguesa (2008), do qual selecionamos 22 verbetes ilustrados da seção da letra $C$ que se referiam ao reino animal. Os verbetes foram categorizados em três grupos distintos, conforme suas características composicionais relacionadas ao enquadramento e à modalidade. As análises apontaram para certo padrão nas estruturas composicional e representacional dos verbetes, bem como apontaram para uma coerência 
v. 11 (esp.)

261-278 ago. 2021

entre os modos verbal e visual. Contudo, percebemos serem exceções ao padrão os verbetes "cachorro", "coruja" e "cavalo". A partir deste trabalho, compreendemos a relevância da Multimodalidade para a Lexicografia Pedagógica, no que tange ao processo de construção de significados. Dessa forma, acreditamos serem promissores estudos futuros que abordem novamente essas questões.

Palavras-chave: Lexicografia Pedagógica. Multimodalidade. Verbete ilustrado.

Abstract: According to the Pedagogical Lexicography (WELKER, 2008; PONTES, 2009; DURAN, 2008), dictionaries should be produced according to the learning needs of the target audience. Moreover, based on the ideas of Multimodality (KRESS, 2015; JEWITT, 2014), we understand that several semiotic modes can be organized to form a greater framework of meaning, thus we realize that illustrated entries are examples of this. The present study aims to analyze illustrated entries, based on the metafunctions described by The Grammar of Visual Design (KRESS; VAN LEEUWEN, 2006). For this, we selected as the object of study the work Aurelinho: Children's Illustrated Dictionary of the Portuguese Language (2008), from which we selected 22 illustrated entries from the section of the letter $\mathrm{C}$, whose theme was the animal kingdom. The illustrated entries were categorized into three distinct groups, according to their compositional features related to framing and modality. The analyzes pointed to a certain pattern in the entries compositional and representational structures, as well as they pointed to coherence between the verbal and visual modes. Nevertheless, we noticed some exceptions to these patterns especially for the entries "cachorro" (dog), "coruja" (owl) and "cavalo" (horse). From this study, we understand the relevance of Multimodality to the Pedagogic Lexicography, in what concerns the process of meaning-making. By this way, we believe that other studies about Multimodality and Pedagogical Lexicography in the future will be promising.

Keywords: Pedagogical Lexicography. Multimodality. Illustrated entries.

\section{Introdução}

Ouso de dicionários em sala deaula como ferramentapedagógica é de grande importância no processo de ensino e aprendizagem. Selecionar um dicionário adequado às necessidades dos estudantes, contudo, não é uma tarefa fácil, tendo em vista a variedade de obras disponíveis no mercado. Inclusive, o próprio Programa Nacional do Livro Didático (PNLD) adota critérios de exclusão e critérios classificatórios para selecionar os dicionários a serem distribuídos nas escolas públicas (BRASIL, 2012). Isso reforça o pensamento de que escolher um dicionário não é algo simples, pois exige, de quem seleciona, compreensão dos objetivos que se têm em relação ao uso dessa ferramenta.

Assim como o processo de escolha, o de elaboração de dicionários é igualmente complexo, visto que essas obras hoje têm amplas funcionalidades que vão além de estabelecer equivalências entre as línguas. Muitos têm sido elaborados pautados em fins didáticos, ou seja, voltados para um público definido e objetivando atender a um fim específico. Nisso consiste a Lexicografia Pedagógica (PONTES, 2009). A 
partir desse conceito entende-se, então, o porquê de haver diferentes tipos de dicionários, de modo que cada tipo visa a atender públicos distintos com necessidades específicas.

Considerando que uma das principais funções do dicionário é possibilitar ao consulente a compreensão do significado das entradas que consulta (LEW, 2010), o que é normalmente abrangido pela definição, entende-se que a diversidade de modos semióticos à qual se tem acesso nos dias atuais é de grande valor para esse processo de construção de significados. Assim, a Multimodalidade visa a explorar a produção de significados a partir da orquestração dos vários modos e meios semióticos disponíveis (SANTOS; PIMENTA, 2014).

Infere-se que esse tema é relevante não somente ao lexicógrafo pedagogo, mas também àqueles que pretendem, de modo geral, trabalhar com dicionários em sala de aula como ferramentas pedagógicas. É importante, ainda, para usuários de dicionários, visto que o conhecimento sobre Multimodalidade pode vir a ser um bom aliado no que se refere à depreensão dos significados das entradas pesquisadas. Considerando a possibilidade de esse usuário ser uma criança, compreendemos que o texto imagético possa permitir a ela, por exemplo, um melhor entendimento do texto escrito. Nesse caso, cabe ao professor estimular a criança consulente a observar como ambos os modos semióticos (imagem e escrita) se organizam entre si e quais os possíveis significados que podem ser extraídos desse texto multimodal.

Sendo assim, com o intuito de estabelecer um diálogo entre Lexicografia Pedagógica e Multimodalidade, o presente trabalho tem como foco analisar verbetes ilustrados de um dicionário infantil monolíngue, a saber, o Aurelinho (2008), de Língua Portuguesa, sob a perspectiva das metafunções descritas na Gramática do Design Visual (GDV), de Kress e van Leeuwen (2006). Para a fundamentação desse trabalho, buscamos, a priori, compreender sobre o que versa o conceito de Lexicografia Pedagógica. Em seguida, traçamos uma breve explicação sobre a microestrutura de um dicionário. Por fim, tecemos noções sobre Multimodalidade e descrevemos a Gramática do Design Visual (GDV), na qual este estudo se pautou para realização das análises dos verbetes.

\section{Lexicografia Pedagógica: do que se trata?}

Conceituar Lexicografia Pedagógica é um trabalho bastante complexo. Segundo Welker (2008), o termo tem sido definido de forma 
v. 11 (esp.)

261-278 ago. 2021

variada, isso quando não há ausência de sua definição. Conforme Pontes (2009, p. 21), a "Lexicografia Pedagógica (ou Didática)" consiste em uma "disciplina definida a partir de duas características fundamentais: a escolha de um público definido e de um fim específico" (PONTES, 2009, p. 21). O autor cita, ainda, Humblé (1998 apud PONTES, 2009), ao afirmar que os dicionários elaborados à luz da Lexicografia Pedagógica visam a resolver os problemas de grupos de aprendizes bem definidos, os quais podem ser iniciantes ou avançados, ou de uma área específica de estudo, ou, ainda, aprendizes de uma determinada língua materna (PONTES, 2009).

Em Duran (2008), encontra-se uma definição mais ampla sobre o que seria a Lexicografia Pedagógica. Segundo a autora, a evolução lexicográfica resultou na introdução desse termo, que, por sua vez, é a "forma como as necessidades dos usuários passaram a ser reconhecidas e interpretadas" (DURAN, 2008, p. 83). Observa, ainda, que "a confecção de dicionários por professores que conheciam as dificuldades dos alunos levou os lexicógrafos a perceberem que uma boa solução pressupõe o conhecimento do problema" (DURAN, 2008, p. 83), isto é, conhecendo as necessidades dos usuários, podese "conceber soluções lexicográficas capazes de superá-las" (DURAN, 2008. p. 83).

Com base nessas informações é possível, então, dizer que a Lexicografia Pedagógica consiste não somente em delimitar um público específico, mas deve, além disso, buscar identificar as principais dificuldades desse público. Essas dificuldades serão o norte para a elaboração do dicionário que melhor o atenda, ou ainda, para a seleção de um dicionário que esteja de acordo com suas necessidades. No que tange à estrutura composicional do dicionário, quanto mais conhecimento o lexicógrafo pedagogo tiver sobre as dificuldades de aprendizagem de seus usuários, mais bem estruturado seu dicionário tenderá a ser, e mais facilmente os objetivos almejados poderão ser atingidos. Além disso, esses conhecimentos podem vir a ser úteis, inclusive, para questões relacionadas à Metalexicografia ${ }^{1}$, tanto para a elaboração, quanto para a análise de obras lexicográficas que se associem a fins pedagógicos.

\footnotetext{
${ }^{1}$ Conforme o depreendido de Pontes (2009), a Metalexicografia (ou Lexicografia Teórica) tem o próprio dicionário como objeto de estudo e as discussões tecidas nesse âmbito servem de fundamento para o fazer lexicográfico.
} 


\section{A microestrutura do dicionário}

A microestrutura do dicionário consiste nos elementos que constituem o verbete. Esses elementos são a entrada, palavra inicial do verbete; a definição, que normalmente consiste na descrição do(s) significado(s) da entrada (LEW, 2010); as acepções, que consistem nos variados sentidos que a entrada pode assumir conforme diferentes contextos (polissemia); as informações gramaticais; as informações fônicas; a pronúncia; as subentradas (se tiver); as marcas de uso, que indicam "o nível de linguagem em que se utiliza cada unidade lexical" (DURAN; XATARA, 2006, p. 52), ou seja, em que área ou em que momento aquela palavra se aplica; os exemplos de uso, marcados por frases que simulam um contexto de uso da palavra (PONTES, 2009) e quaisquer outros elementos ao verbete agregados, tais como as imagens, por exemplo.

No que tange à estrutura de verbetes em dicionários infantis, a partir da observação de algumas obras desse tipo, pôde-se perceber que há evidente utilização de elementos visuais. Recursos não-verbais imagéticos, tais como ilustrações, fotografias, desenhos e outros tipos de imagem (LEW, 2010), são constantemente solicitados para compor verbetes de dicionários infantis dados os seus papéis pedagógicos em "auxilia[r] o aprendiz a visualizar conceitos" (DURAN; XATARA, 2006, p. 61). Esses recursos, portanto, "transmitem aspectos dificilmente apreensíveis pela descrição verbal [e] reforçam o aprendizado e a retenção do léxico, pois constituem um recurso a mais para a ancoragem do conhecimento na memória do aprendiz" (DURAN; XATARA, 2006, p. 61). A partir dessas informações reforça-se, portanto, a importância de se compreender sobre o que trata, então, a Multimodalidade.

\section{Multimodalidade e a Gramática do Design Visual}

Segundo Kress (2015), a língua (falada ou escrita), por muito tempo soberana, tem sido agregada a outros meios semióticos, em novas formas de constituir textos e de expressar e construir sentido. Essa nova concepção de expressão e construção de sentido denominase Multimodalidade.

Com o conceito de Multimodalidade, tem-se, ainda, a noção de modos comunicativos, isto é, a língua, tanto falada, quanto escrita, assim como a imagem, o som, o gesto, o olhar, a postura, dentre 
v. 11 (esp.)

261-278 ago. 2021

outros (JEWITT, 2014), é considerada apenas um modo semiótico, por meio do qual se pode tecer significados. Uma vez que os modos são e geram significados parciais, a completude dos significados se dá por meio da combinação entre os modos semióticos (KRESS, 2015). Essas informações corroboram a noção de letramento multimodal descrita por Catto (2013), que afirma que a compreensão e a produção de significados em textos multimodais constituem-se a partir da combinação entre os mais variados modos comunicativos. Logo, considerando que o verbete é um exemplo de texto multimodal (já que compreende mais de um modo semiótico em sua estrutura), entende-se, então, a relevância da Multimodalidade para a Lexicografia Pedagógica.

Modos semióticos não verbais ligados à imagem (fotos, desenhos, gráficos, tabelas, ilustrações, por exemplo) são bastante comuns em dicionários (LEW, 2010), pelo menos a partir do que se observa em versões impressas de dicionários infantis. Dessa forma, compreender as questões sobre leitura de imagem tecidas pela Gramática do Design Visual (GDV) se faz necessário.

A GDV, idealizada por Kress e van Leeuwen (2006), propõe uma releitura das metafunções da linguagem contempladas pela Linguística Sistêmico-Funcional (LSF) de Halliday ${ }^{2}$. A releitura consiste em estender, para o modo visual, o que a LSF aborda para a língua falada e escrita. Sendo assim, baseada nas metafunções ideacional, interpessoal e textual da LSF, a GDV sugere suas metafunções representacional, interacional e composicional, respectivamente.

A metafunção representacional subdivide-se, ainda, em narrativa ou conceitual, e está ligada às formas com que os indivíduos representam o mundo em que vivem, estabelecendo relações entre os participantes e os processos (transações). A metafunção representacional narrativa caracteriza-se pela presença de vetores (simbolizados por um olhar ou um movimento de braço, por exemplo) traçados entre os participantes envolvidos no processo. Os processos podem ser acionais ou reacionais e ambos podem se caracterizar, ainda, como transacionais ou não-transacionais. No processo acional transacional é possível observar um vetor entre o ator (praticante da ação) e a meta (para onde a ação se direciona). Já no processo acional não-transacional, a meta não é visível ao observador/leitor da imagem. Há ainda a possibilidade

\footnotetext{
${ }^{2}$ Conferir: HALLIDAY, Michael Alexander Kirkwood; MATTHIESSEN, Christian Mathias Ingemar Martin. Halliday's introduction to Funcional Grammar. $4^{\text {th }}$. ed. London/New York: Routledge, 2014 .
} 
de ambos os participantes do processo serem, ao mesmo tempo, atores e metas entre si, caracterizando um processo acional bidirecional. Quanto aos processos reacionais, compreende-se a presença de um reator, participante que exerce a função de observador, sendo o observado denominado fenômeno. Caso o fenômeno seja visível ao observador/ leitor da imagem, o processo reacional é transacional, caso não seja, é não-transacional (KRESS; VAN LEEUWEN, 2006).

Já a metafunção representacional conceitual não apresenta vetores entre os participantes e seus processos podem ser considerados como classificacionais, analíticos ou simbólicos. Nos processos classificacionais, os participantes podem assumir o papel de superordenados ou de subordinados. Considera-se superordenado o participante detentor da informação principal, a qual vem a ser detalhada ou caracterizada pelos demais participantes, os subordinados. Um exemplo desse tipo de representação pode ser visto na composição de um organograma empresarial (KRESS; VAN LEEUWEN, 2006).

No que tange aos processos analíticos, a relação estabelecida entre os participantes é de parte(s)-todo, sendo o todo denominado portador e a(s) parte(s), atributo(s) possessivo(s). Como exemplo, é possível destacar o quebra-cabeças, no qual o objeto completamente montado seria o portador e cada peça, um atributo possessivo. O processo analítico pode ser tanto não-estruturado, quando o todo (portador) não é explícito, quanto estruturado (portador explícito), podendo ser identificado como exaustivo (sem lacunas a serem exploradas) ou inclusivo (apresenta lacunas). O processo analítico pode se organizar, ainda, em forma de linhas do tempo, caracterizando, assim, um processo analítico temporal (KRESS; VAN LEEUWEN, 2006).

Já quando o processo está relacionado ao que os participantes são ou significam há um processo simbólico. Os processos simbólicos podem ser atributivos, quando há relação entre os atributos simbólicos e o portador, ou subjetivos, quando se percebe ausência de atributos simbólicos, mas o significado pode ser estabelecido por meio da presença de elementos tais como cores, variação de foco, iluminação e outros (KRESS; VAN LEEUWEN, 2006).

Quanto à metafunção interacional (ou interativa), é possível compreender que consiste nas relações entre os elementos do texto visual e seu observador/leitor, prevendo questões como a direção do olhar (contato), a distância social, os ângulos (perspectiva ou ponto de vista) e a modalidade. A direção do olhar pode ser marcada tanto por 
v. 11 (esp.)

261-278 ago.

2021

demanda, no caso de o olhar do participante da imagem fixar-se no olhar do observador, quanto por oferta, quando o olhar do participante é distante do de quem visualiza a imagem (KRESS; VAN LEEUWEN, 2006).

Quanto à distância social, esta contempla as relações entre participante e observador no que tange ao posicionamento dos participantes nos planos (se aberto, se fechado ou se médio) da imagem. Quando em plano aberto, há menor envolvimento entre as partes, já que os participantes podem ser vistos por inteiro, passando uma ideia de distanciamento. Quando em plano médio, os participantes são vistos apenas em parte, geralmente da cabeça até o joelho. Ainda que mais próximos em relação aos representados em plano aberto, essa disposição ainda aponta certo distanciamento social. Já o plano fechado (ou close-up), a ideia de proximidade é bastante evidente, pois é possível ver mais detalhes do participante (tais como expressões faciais) e isso passa uma ideia de maior intimidade entre este e o observador (KRESS; VAN LEEUWEN, 2006).

Em relação aos ângulos, estes expressam a perspectiva visual tanto de quem observa, quanto de quem é observado. Quando sob a perspectiva top-down (de cima para baixo), tem-se a ideia de que o observador exerce poder sobre o participante. Na perspectiva contrária, a buttom-up (de baixo para cima), a ideia de poder é inversa, retratando o participante como um inquisidor em relação ao observador. Já sob a perspectiva do ângulo frontal, ambos, observador e participante, são colocados em patamar de igualdade (KRESS; VAN LEEUWEN, 2006).

Já a modalidade está relacionada ao valor de verdade da imagem, ou seja, refere-se à noção de realidade que a imagem vem a passar. A modalidade pode ser naturalística, quando a representação se dá por fotos, ou sensorial, quando na imagem há algum efeito causando esse tipo de impacto. Há ainda as modalidades científica e abstrata, cujos nomes já explicam suas características (KRESS, VAN LEEUWEN, 2006; NASCIMENTO; PONTES, 2011).

Para finalizar, a metafunção composicional visa a contemplar questões estruturais, tais como o valor da informação, a saliência e o enquadramento. O valor da informação pode ser observado a partir das relações dado/novo, ideal/real e centro/margem. Na relação dado/novo, tem-se o participante da esquerda como dado (informação conhecida, principal) e o da direita, como novo (informação acrescida). Na ideal/ real, a relação é semelhante à anterior, mas observada nas posições 
cima/baixo, em que o ideal (cima) consiste na informação principal ou já conhecida e o real (baixo), é a nova informação. Quanto à relação centro/ margem, a informação principal vem ao centro e as complementares, às margens. Essa composição é facilmente observada em representações conceituais.

No que tange à saliência, compreende-se como quaisquer recursos que visem a conferir destaque a um ou mais elementos da composição. São exemplos: as diferenciações por cores (cores destacando uma informação); as diferenças de foco (quanto mais nítido, maior a importância conferida); as posições nos planos (informações em primeiro plano têm maior relevância que as de plano de fundo); e as diferenças de tamanho (maior destaque é conferido a elementos representados em tamanho maior). Já o enquadramento está relacionado à totalidade da composição e abrange sua formatação de um modo geral. (KRESS; VAN LEEUWEN, 2006). Consiste na maneira como os elementos são conectados ou desconectados entre si, podendo compor identidades tanto em conjunto, quanto individualmente (JEWITT; OYAMA, 2008). O enquadramento pode ser tanto linear, no qual é possível prever o caminho de leitura, quanto não-linear, no qual os caminhos de leitura não são facilmente dedutíveis devido às múltiplas possibilidades trazidas pela estruturação. (KRESS; VAN LEEUWEN, 2006).

Tendo em vista a natureza multimodal do verbete ilustrado, compreendemos serem essas questões bastante úteis tanto para quem elabora, quanto para quem lê dicionários. Dessa forma, visamos a aplicar as informações contempladas pelas metafunções da GDV na prática da análise destes textos multimodais: os verbetes ilustrados.

\section{Metodologia}

Para o presente trabalho, de cunho exploratório-qualitativo, selecionamos a obra lexicográfica Aurelinho: Dicionário infantil ilustrado da língua portuguesa (2008), o qual foi elaborado para atender a crianças em fase de alfabetização. Além disso, o dicionário tem como proposta utilizar imagens como forma de complementar as informações fornecidas em alguns verbetes e tornar a leitura feita pelo público-alvo mais lúdica e atrativa.

Em relação à seleção do corpus do nosso estudo, optamos por contemplar a seção correspondente à letra $C$ do dicionário, uma vez que constatamos ser esta a seção dotada de maior número de verbetes ilustrados (22 verbetes) quando comparada às demais. Dos 22 verbetes 
v. 11 (esp.)

261-278 ago. 2021

observados, preferimos analisar aqueles que se referem ao reino animal, visto que consistem em metade do total de verbetes ilustrados compreendidos na seção, totalizando 11 verbetes.

Para a análise, os verbetes foram divididos em três grupos distintos: o GRUPO 1, referente às fotografias aplicadas em um contexto específico, no qual se inserem 05 verbetes: cachorro, cágado, carneiro, coelho e coruja; o GRUPO 2, que abrange fotografias com ausência de enquadramento em um contexto, no qual estão outros 05 verbetes: camaleão, caramujo, cascavel, cavalo e crustáceo; e o GRUPO 3, no qual está inserido apenas um verbete (canguru), cuja imagem consiste em uma ilustração por desenho, ou seja, não se enquadra como fotografia. Essa divisão tem como finalidade agrupar verbetes que têm características em comum. Entendemos que esse recurso torna mais didática e organizada nossa análise, que toma como base algumas categorias relevantes das três metafunções descritas na Gramática do Design Visual (GDV), de Kress e Van Leeuwen (1996). Consideramos, ainda, para a análise dos verbetes, as teorias supracitadas da Lexicografia Pedagógica e, por fim, fazemos uma reflexão entre a parte escrita e a parte visual, analisando a questão da coerência entre o texto escrito do verbete e a imagem escolhida para ilustrá-lo. O desenvolvimento desses procedimentos pode ser visto a seguir.

\section{Análise do corpus: os verbetes vistos à luz da GDV}

Nesta seção do artigo, desenvolvemos a análise dos verbetes com base no alicerce teórico da GDV. Como dissemos anteriormente, o primeiro grupo de verbetes que abordamos é o GRUPO 1: cinco fotografias inseridas em um contexto específico. Depois, partimos para o GRUPO 2: cinco fotografias não enquadradas em um contexto específico. Por fim, analisamos o GRUPO 3: uma ilustração em formato de desenho.

Verbetes categorizados como do GRUPO 1

As imagens dos verbetes do GRUPO 1 (Figura 1) são fotografias e têm, por característica principal, a existência de uma circunstância locativa, isto é, um lugar em que o participante principal da imagem está inserido. No caso deste estudo, os participantes são animais. 
Figura 1 - Verbetes do GRUPO 1: cachorro, cágado, carneiro, coelho e coruja

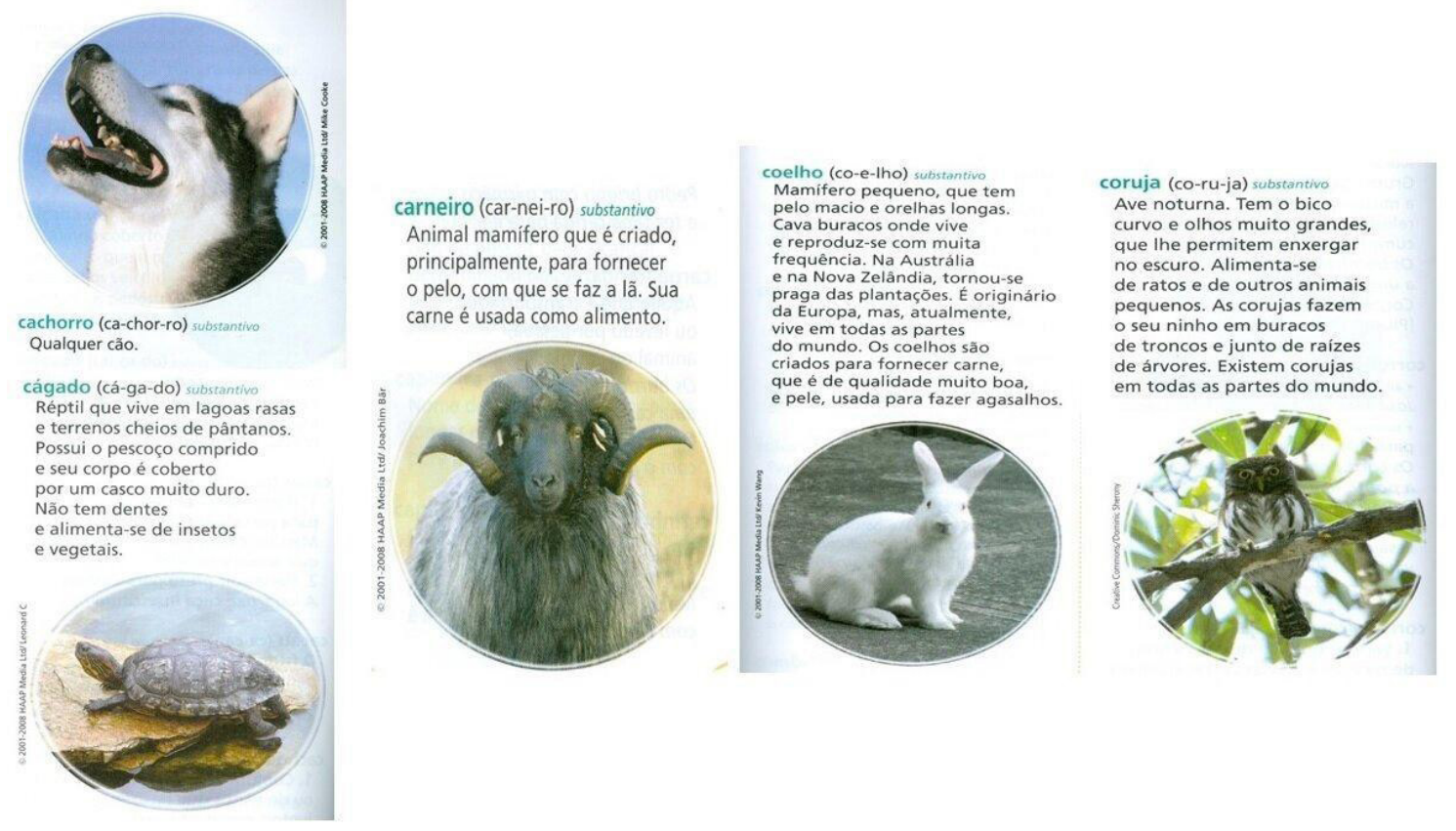

Fonte: Aurelinho (2008, p. 63, 64, 72, 83, 94).

Ao considerarmos a metafunção representacional, observamos que as imagens do GRUPO 1 podem ser consideradas conceituais, visto que não são identificados vetores marcando ações de um ator para uma meta. Podemos compreender, ainda, se considerarmos a unidade do verbete (texto verbal e visual) como uma única imagem, os processos como classificacionais, sendo o texto imagético o elemento superordenado e a escrita o elemento subordinado, uma vez que a definição detalha o que se vê na imagem. O verbete coruja, contudo, é uma exceção a essa afirmativa, visto que, enquanto no texto verbal está descrito "ave noturna", a fotografia representa uma coruja de hábitos diurnos, o que gera incoerência na composição do todo do verbete como texto multimodal.

Em relação aos aspectos interacionais, observamos que as imagens dos verbetes são de modalidade naturalística e que a direção do olhar varia conforme a imagem. Nos verbetes "coelho, carneiro e coruja", observamos olhar de demanda, enquanto nos verbetes cachorro e cágado, o olhar é de oferta. Quanto à distância social, a maioria dos verbetes apresentam o plano aberto, tornando a visualização dos animais melhor, visto que são mostrados de corpo inteiro. Já os ângulos, na maioria das imagens, são frontais. Exceções a essas características, contudo, são observadas no verbete cachorro, que se apresenta em 
v. 11 (esp.)

261-278 ago.

2021

plano fechado (close-up) e ângulo buttom-up, e no verbete carneiro, cuja imagem é disposta em plano médio. Acreditamos que ambas as exceções sejam propositais e que a intenção do lexicógrafo foi trazer à criança consulente uma proximidade social com os animais em questão. No caso do verbete cachorro, por exemplo, é possível uma leitura de que esse animal é colocado em posição de herói, de amigo. Destacamos, ainda, que o texto verbal desse verbete é muito curto e não apresenta, como nos demais, informações detalhadas acerca do exposto pela imagem, conferindo a esse modo semiótico maior destaque.

No que diz respeito aos aspectos composicionais identificamos haver uma forte estruturação, ou seja, há uma delimitação bem marcada da imagem em relação ao texto escrito. As imagens desse grupo são salientadas por círculos ou elipses e o enquadramento é não-linear, ou seja, a leitura do verbete pode ser iniciada tanto pela parte escrita quanto pela parte imagética. A disposição informativa da linguagem verbal e da linguagem imagética segue a relação ideal/real e isso ocorre em quase todos os verbetes do GRUPO 1, os quais trazem o texto verbal na posição do ideal (em cima), e a imagem, na posição do real (embaixo), com exceção do verbete cachorro, cuja relação ocorre de forma contrária. Compreendemos, ainda, que essa forma de estruturação em trazer o texto verbal na posição ideal e a imagem na posição real visa a destacar o texto escrito como informação mais relevante e a imagem como um complemento da escrita. Observamos, portanto, que há uma padronização estrutural e acreditamos ser essa uma característica positiva, visto que pode vir a tornar o manuseio do dicionário uma tarefa mais fácil para a criança. Em relação à exceção (verbete cachorro), contudo, acreditamos ser de cunho intencional do lexicógrafo, a fim de que a criança consulente se volte primeiramente para a imagem, a qual pode ser considerada como amplamente conhecida pelo público infantil.

\section{Verbetes categorizados como GRUPO 2}

As imagens dos verbetes do GRUPO 2 (Figura 2) também são fotografias e têm como ponto em comum o fato de não haver uma circunstância locativa, ou seja, o objeto principal da imagem não está inserido em um contexto específico, havendo apenas o fundo branco da página. 


\section{Figura 2 - Verbetes do GRUPO 2: camaleão, caramujo, cascavel, cavalo e crustáceo}

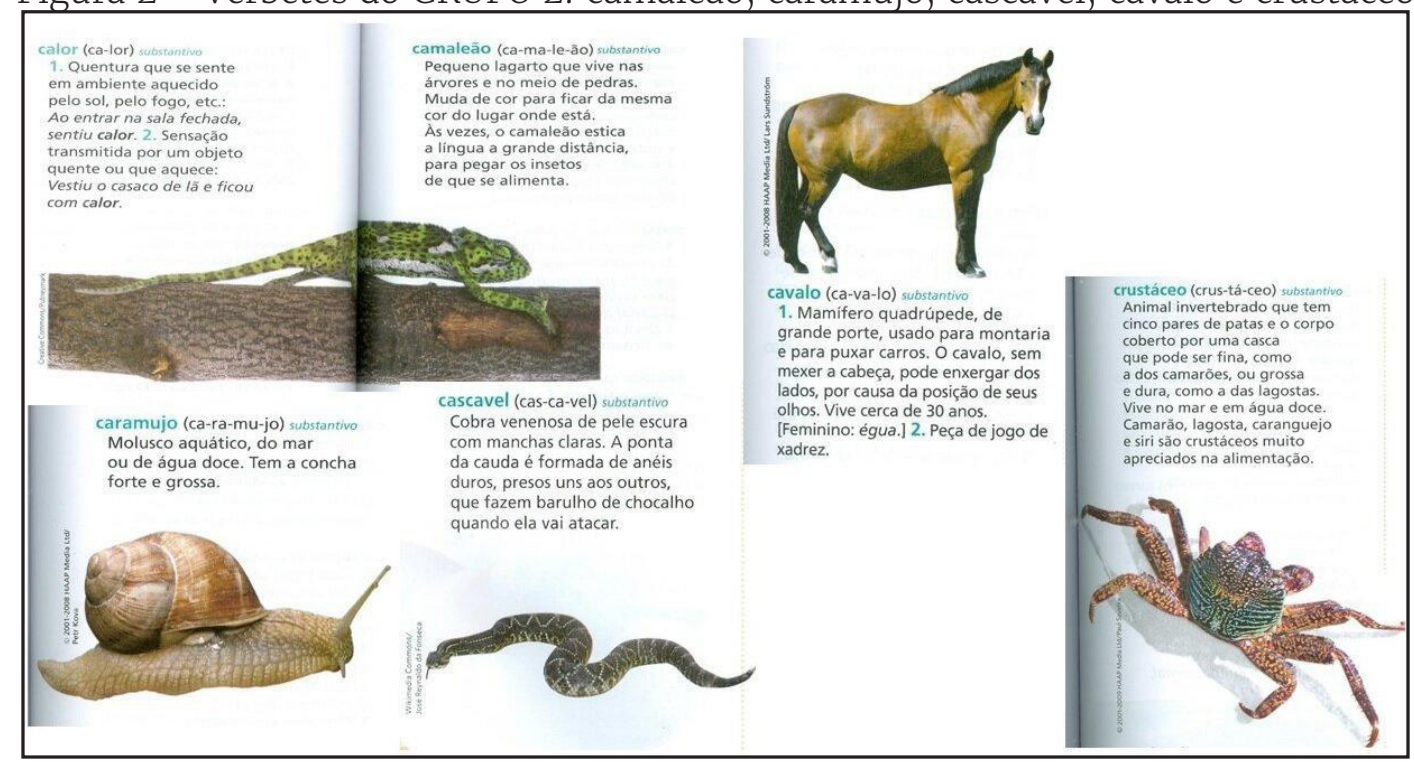

Fonte: Aurelinho (2008, p. 67, 71, 74, 75, 97).

Com base na metafunção representacional, assim como os verbetes do GRUPO 1, os verbetes do GRUPO 2 podem ser considerados como conceituais, tendo em vista a ausência de vetores, conforme explanamos anteriormente. Os processos, novamente, podem ser compreendidos como classificacionais e observamos, mais uma vez, que os verbetes são, majoritariamente, organizados de forma a manter uma relação coesa entre a escrita e a imagem, pois as fotografias selecionadas dos animais são representações da informação do texto escrito. Consideramos, contudo, o verbete cavalo como uma exceção, visto que apresenta duas acepções (cavalo como o animal e cavalo como a peça de xadrez), mas a ilustração do verbete só contempla a acepção de cavalo como animal. Logo, é possível compreender que a representatividade da segunda acepção fica prejudicada.

Outro verbete a ser destacado é o da entrada crustáceo, cuja representatividade da imagem compreendemos não estar plenamente alinhada com o texto verbal. Por referir-se a um subfilo do filo artrópode, a palavra crustáceo designa um conjunto de seres que podem ser classificados sob uma mesma denominação, o que torna difícil a escolha de uma imagem que represente fielmente um conjunto de seres tão diversos entre si. A escolha da imagem de um único ser (caranguejo) para representar o conjunto (crustáceo) pode gerar, na criança consulente, uma ideia equivocada de que crustáceo seria somente aquele ser representado, ainda que a definição do verbete destaque outros exemplos. 
v. 11 (esp.)

261-278 ago. 2021
Quanto aos aspectos interacionais, todos os verbetes que compõem o GRUPO 2 apresentam imagens de modalidade naturalística (fotografias) e, no que diz respeito à direção do olhar, somente a imagem do verbete cavalo está em demanda, estando os demais em oferta. Entendemos que a intenção desse olhar de demanda é de aproximar o animal representado na imagem à criança consulente, como se a convidasse para um passeio, por exemplo. Em relação à distância social, os verbetes desse grupo apresentam-se em plano aberto, e os ângulos são frontais, tal como a maioria dos verbetes do GRUPO 1. Ainda que isso denote um maior distanciamento do consulente em relação aos elementos da imagem (animais), a disposição em plano aberto permite uma melhor visualização desses elementos, visto que os animais são mostrados de corpo inteiro. Por essa questão, consideramos a escolha do plano aberto adequada para representar o animal em sua totalidade.

Quanto aos aspectos composicionais, compreendemos que os verbetes do GRUPO 2 apresentam enquadramento não-linear e são, ainda, de estruturação fraca, visto que não há quaisquer elementos delimitando o texto visual separando-o do texto verbal. Assim como nos verbetes do GRUPO 1, o valor da informação dos verbetes do GRUPO 2 traz, predominantemente, a relação ideal/real, na qual o texto verbal vem disposto na posição do ideal e a imagem, na posição do real. Conforme dito anteriormente, consideramos que essa forma de estruturar, concebendo uma padronização, confere organização ao dicionário e, consequentemente, pode facilitar o manuseio por parte do consulente, no caso, a criança. Todavia, assim como observado no verbete cachorro, do GRUPO 1, o verbete cavalo foge dessa tendência, uma vez que a imagem vem na posição de ideal e o texto escrito, na posição de real, conferindo à imagem uma posição de maior importância em relação ao texto escrito. Embora configure uma quebra de padronização, compreendemos ser esse fato intencional, a fim de aproximar a criança consulente ao animal representado.

\section{Verbete categorizado como GRUPO 3}

A imagem do verbete do GRUPO 3 (Figura 3) difere-se das imagens dos outros grupos, visto que a ilustração é por meio de um desenho. Essa imagem não apresenta circunstância locativa, nem delimitações que a destaquem do restante do verbete. 
Figura 3 - Verbete do GRUPO 3: canguru

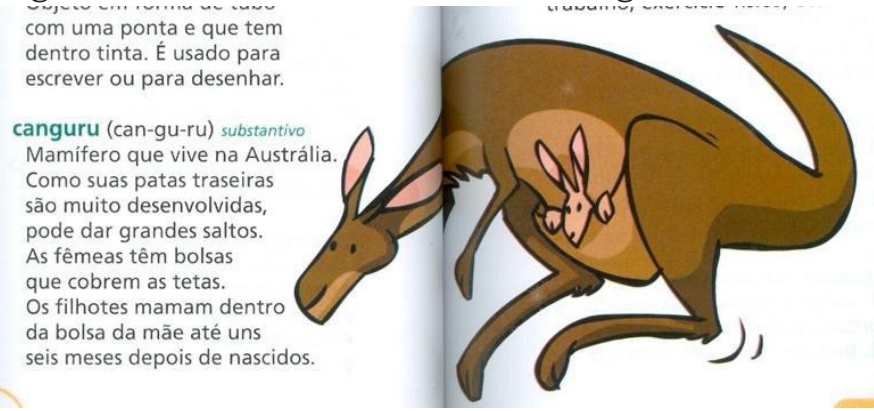

Fonte: Aurelinho (2008, p. 68).

No que tange à metafunção representacional, o verbete diferenciase dos outros até então analisados neste trabalho, uma vez que consiste em uma estrutura narrativa. Na imagem, nota-se que se trata de uma fêmea do canguru, a qual é representada pela ação de um salto, que pode ser percebido pela inclinação do animal ilustrado. Essa inclinação forma um vetor dos pés do animal para a parte inferior esquerda da página do livro, indicando o direcionamento do animal para este sentido. Os riscos traçados no desenho, destacados nos calcanhares do animal, também geram a ideia de movimento, confirmando a percepção de que a estrutura é narrativa.

Quanto à metafunção interacional, percebemos que a modalidade é não naturalística, visto que a imagem é um desenho e não uma fotografia. Uma vez que o desenho é algo comum ao universo infantil, acreditamos que a escolha desse modo semiótico tenha sido, novamente, algo intencional, possivelmente com o intuito de aproximar a criança consulente ao animal representado na imagem. Observamos, ainda, que a direção do olhar é de oferta, que o ângulo é frontal e que a distância social é marcada pelo plano aberto, ou seja, o animal pode ser visualizado por completo permitindo que a criança consulente tenha ampla noção do que seria um canguru.

Outro aspecto que diferencia o verbete em questão dos demais já analisados, no que diz respeito aos aspectos composicionais, é que em vez de o valor da informação estar estruturado conforme a relação ideal/real, sua organização baseia-se na relação dado/novo. No caso, o texto escrito ocupa a posição do dado (esquerda) e a imagem, a posição do novo (direita), apontando, assim como já visto na maioria dos verbetes dos GRUPOS 1 e 2, o texto escrito como o modo semiótico em evidência. Tendo em vista o distanciamento social entre o animal, canguru, e as crianças consulentes, visto que esse animal não faz parte da fauna brasileira, considera-se, portanto, adequado e coerente o posicionamento da imagem em relação ao texto do verbete canguru. 
v. 11 (esp.)

261-278

ago.

2021

\section{Considerações finais}

Conforme observamos, a partir das análises feitas neste trabalho, percebemos que o dicionário Aurelinho (2008) abraça as questões da Multimodalidade, visto que apresenta um bom número de verbetes ilustrados. Na realidade, o dicionário em sua totalidade é dotado de elementos visuais que se relacionam com os elementos verbais e isso é, de modo mais evidente, percebido na composição estrutural dos verbetes. Embora tenhamos identificado, a partir do corpus selecionado para a análise, que os verbetes apresentam, quanto à relação escritaimagem, uma tentativa de padronização estrutural, percebemos que há, ainda, de modo geral, algumas arestas a serem aparadas.

Como padrão, a maioria dos verbetes analisados evidenciou o texto verbal, visto que esse modo semiótico normalmente era posicionado como dado, enquanto a imagem assumia a posição de novo, na relação dado/ novo. As imagens, que na maioria das vezes consistiam em fotografias, apresentavam, de certa forma, um papel de complementaridade ou de exemplificação. Acreditamos, portanto, que essa padronização seja vantajosa no que se refere ao manuseio do dicionário, pois entendemos que encontrar informações em uma obra que segue um padrão é mais fácil e mais rápido que encontrar informações em obras que não apresentem essa característica. Identificamos, contudo, algumas quebras nesse padrão, as quais puderam ser observadas nos verbetes cachorro (GRUPO 1), cavalo (GRUPO 2) e canguru (GRUPO 3). Essa quebra, no entanto, compreendemos ter sido intencional por parte do lexicógrafo, a fim de proporcionar à criança consulente novas percepções durante a consulta, as quais podem ser, por exemplo, uma maior afinidade com o animal representado (cachorro, cavalo), uma familiaridade com o modo semiótico trazido (canguru sob a forma de desenho) entre outras.

Outra questão que consideramos ser vantajosa é o fato de as imagens serem representadas por fotografias. Esse aspecto naturalístico, a nosso ver, pode vir a ampliar as possibilidades interpretativas e a facilitar o processo de construção do significado, já que as fotografias destacadas nos verbetes representam algo próximo do real. Dessa forma, ainda que a criança consulente não saiba, não conheça, ou não consiga depreender o significado pelo aspecto verbal, a imagem fotográfica pode, de certa maneira, mostrar-lhe sobre o que trata o verbete, já que representa uma proximidade do real. Ainda assim, observamos a presença de ilustrações pictóricas (desenhos), tal como visto no verbete canguru 
(GRUPO 3) que, embora mais distante do naturalístico, compreendemos que o uso de desenhos remete mais à realidade do público infantil e podem vir a ser, inclusive, atrativos dentro do dicionário. Logo, entendemos que foram inseridas de forma intencional pelo lexicógrafo, possivelmente com esse intuito. É importante se destacar, ainda, que o texto escrito e a imagem, independentemente de esta ser pictórica ou fotográfica, devem ser coerentes entre si. De fato, na maioria dos verbetes analisados constatamos essa coerência, mas percebemos ser o verbete coruja (GRUPO 1) uma exceção, devido a divergências entre as informações da definição e o representado na imagem, fato que pode vir a confundir o consulente no processo de construção de sentido.

A partir deste trabalho, conseguimos perceber uma parcela da importância da Multimodalidade para a Lexicografia Pedagógica, que objetiva a produção de dicionários (normalmente com fins didáticos) para públicos específicos. De fato, considerar escrita e imagem como modos integrantes de um contexto maior compreendido pelo verbete pode vir a contribuir largamente para o processo de construção de significados. Considerando que as teorias multimodais constituem uma poderosa ferramenta na produção de materiais didáticos, e compreendendo o dicionário como um exemplo desse tipo de material, entendemos a necessidade de mais pesquisas relacionadas aos possíveis diálogos entre Lexicografia Pedagógica e Multimodalidade.

\section{Referências}

BRASIL. Ministério da Educação, Secretaria de Educação Básica. PNLD 2012: Dicionários. Brasília, DF, 2012.

CATTO, Nathalia Rodrigues. A relação entre o letramento multimodal e os multiletramentos na literatura contemporânea: alinhamentos e distanciamentos. Fórum linguístico, Florianópolis, v. 10, n. 2, p. 157-163, abr./jun. 2013.

DURAN, Magali Sanches. A lexicografia pedagógica e sua contribuição para a mudança do paradigma lexicográfico. In: XATARA, Cláudia; BEVILACQUA, Cleci; HUMBLE, Philippe. (Org.). Lexicografia pedagógica: pesquisas e perspectivas. Florianópolis: UFSC/NUT, 2008. p. 82-93.

DURAN, Magali Sanches; XATARA, Cláudia Maria. A Metalexicografia Pedagógica. Cadernos de Tradução, v. 2, n. 18, p. 41-66, 2006. DOI: https:// doi.org/10.5007/\%25x. Disponível em: https://periodicos.ufsc.br/index.php/ traducao/article/view/6870/6448. Acesso em: 27 set. 2020.

FERREIRA, Aurélio Buarque de Holanda. Aurelinho Dicionário Infantil Ilustrado da Língua Portuguesa. 2. ed. Curitiba: Editora Positivo, 2008. 
v. 11 (esp.)

261-278 ago. 2021
JEWITT, Carey. An introduction to multimodality. In: JEWITT, Carey (ed.) The Routledge Handbook of Multimodal Analysis. $2^{\text {nd }}$. ed.London/New York: Routledge, 2014, p. 15-30.

JEWITT, Carey; OYAMA, Rumiko. Visual meaning: a social semiotic approach. In: LEEUWEN, Theo van; JEWITT, Carey. Handbook of visual analysis. London: SAGE, 2008. p. 134-156.

KRESS, Gunther; van LEEUWEN, Theo. Reading Images: the grammar of visual design. $2^{\text {nd. }}$ ed. London/New York: Routlege, 2006.

KRESS, Gunther. Semiotic work: Applied Linguistics and a social semiotic account of Multimodality. AILA Review - Applied Linguistics Research. Critical Approaches to production, performance and participation, v. 28, p. 49-71, 2015.

LEW, Robert. Multimodal Lexicography: the representation of meaning in electronic dictionaries. Lexikos Journal, v. 20, p. 290-306, 2010.

NASCIMENTO, Francisco Iací do; PONTES, Antônio Luciano. A multimodalidade no Dicionário Aurélio Ilustrado. In: SIMPÓSIO INTERNACIONAL DE LETRAS E LINGUÍSTICA, 13., 2011, Uberlândia. Anais[...]. Uberlândia: EDUFU, 2011. p. 1694-1709.

PONTES, Antônio Luciano. Léxico e Dicionário. In: PONTES, Antônio Luciano. Dicionário para uso escolar: o que é como se lê. Fortaleza: EDUECE, 2009. Cap. 1. p. 17-56.

SANTOS, Zaíra Bomfarte dos; PIMENTA, Sônia Maria Oliveira. Da Semiótica Social à Multimodalidade: a orquestração de significados. CASA - Cadernos de Semiótica Aplicada, v. 12, n. 2, p. 295-324, 2014.

WELKER, Herbert Andreas. Dicionários para aprendizes de línguas estrangeiras. In: WELKER, Herbert Andreas. Panorama geral da Lexicografia Pedagógica. Brasília: Thesaurus, 2008. Cap. 4. p. 117-294. 